\title{
Market moods and network dynamics of stock return: The bipolar behavior
}

\begin{abstract}
We show that a simple mood-separable preference in a network study of stock returns captures a variety of stylized facts regarding stocks' provisional (ab)normal behavior. These behaviors are articulated in a multi-state complete Euclidean network model that specifies the existence, direction and magnitude of a self-organized dynamics for each individual stock during abnormal market moods. In the empirical setting, we apply suggested model along with two established visual approaches (MDS and AHC) for benchmark purposes. Results reveal different levels of erratic return dynamics for each stock and the entire market in different abnormal market moods. We model and interpret these self-organized dynamics as evidence of stocks' and market's bipolar behavior.
\end{abstract}

\footnotetext{
Ali Irannezhad Ajirlou ${ }^{a}$, Hamidreza Esmalifalak ${ }^{\mathrm{b}, *}$, Maryam Esmalifalak ${ }^{\mathrm{c}}$, Sahar Pordeli Behrouz ${ }^{\mathrm{d}}$, Babak Soltanalizadeh ${ }^{\mathrm{e}}$

${ }^{a}$ Department of Management, Science and Research Branch, Azad university, Arak, Iran

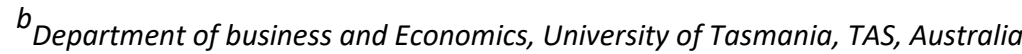

${ }^{c}$ Department of Computer Engineering, University of Houston, Houston, TX, USA

${ }^{d}$ Department of Electrical and Computer Engineering, Science and Research Branch, IAU, Tabriz, Iran

${ }^{e}$ Department of Mathematics, University of Houston, Houston, TX, USA
}

\section{KEYWORDS}

Complete Euclidean Network, Alpha measure, Stocks' bipolar behavior, Market's bipolar behavior,

\section{Introduction}

In recent years, the research of complex systems has gradually expanded from mathematics, physics and biology to sociology, economics and finance. The intuition behind this extension is the emersion of modern socioeconomics systems which are highly interdependent with an intricate financial structure. Recent studies conducted by econophysicists have reported that the complex dynamics of stock returns contain many applications of complex system analysis (Huang, Yao, Zhuang, \& Yuan, 2017; Lillo, Farmer, \& Mantegna, 2003; Mantegna \& Stanley, 2000; McCauley, 2006; Muñoz Torrecillas, Yalamova, \& McKelvey, 2016; Pan \& Sinha, 2007; Yang \& Yang, 2008). For instance, it is shown that the return behavior has sudden trend changes for a large number of stocks or, in an unsynchronized fashion, effecting only a few stocks at the same time (see (Hirshleifer \& Shumway, 2003; Olson, 2006)).

According to these studies, the picture of stock market as a group of interacting traders that are regularly adapting to new information, and reflecting them in stock prices, seems to be a very abstract picture of how real stock markets operate. This notion is somehow justified in the past literature where trying to construct robust theoretical frameworks for financial markets

* Corresponding author. Hamidreza Esmalifalak Tel: +61-0 043-563-9100 E-mail esmalifalak.hamidreza@utas.edu.au Other authors: ali.irannezhada@gmail.com Mesmalifalak2@uh.edu s.pordeli1@gmail.com babak@math.uh.edu 
behavior has been extremely controversial and challenging issue (Lo, 2004; Small, 2005). On the other hand, explanations of these complexities from decision science and market mass psychology accuse traders' emotional eccentricities, where these can be shaped by many controlling stimuli such as the power of mass psychology, risk tolerance and misguided thinking (Hilton, 2001; Mantegna \& Stanley, 2000; Nofsinger, 2016; Sornette, 2003). In this view, the time evolution of stock return, and the complexity behind it, is closely connected with the fundamental nature of human beings (Lo, 2004; Vieito, da Rocha, \& Rocha, 2015). From the methodological perspective, many studies have considered modeling the correlation networks between stock returns (Kristoufek \& Vosvrda, 2013; Mantegna \& Stanley, 2000). An alternative approach focuses on the stocks' complex network structure via the hierarchical linkages among stocks (BAYDILLi, BAYIR, \& TÜRKER, 2017; Boginski, Butenko, \& Pardalos, 2006; Esmalifalak, Ajirlou, Behrouz, \& Esmalifalak, 2015; Kantar, Deviren, \& Keskin, 2011; Mantegna, 1999; Ulusoy et al., 2012). These networks and the extracted information are analyzed and compared, using clusters, cliques and connectivity.

Despite the demonstrated efficacy of these approaches especially in dealing with the static network structures, they do not provide a systematic approach that reports aggregate behavior under changing market condition. In this study, we suggest a statedependent network study which highlights the synergies created from the application of complex network theory to the stock market behavioral analysis. In the methodological context, we introduce a complete Euclidean network (CEN) model that relies on the application of a spatial measure (Euclidian distance metric) instead of the correlation measure for scaling (dis)similarities. For testing the validity of numerical results, we will look at the visual reports of the agglomerative hierarchical clustering (AHC) and multidimensional scaling (MDS)1. In the CEN model, we capture change in the market mood dependent return patterns as evidence of Stocks Bipolar Behavior SBB. Using this elementary definition of bipolar behavior, the primary focus of Sec. 2 is to specify the theoretical background that accounts for the existence of the bipolar behavior in stock market literature.

The outline of the paper is as follows. The next section briefly reviews prior studies regarding the mass psychology of stock market and the practices of traders over time. In section three, we present the research methodology and model. The first phase of the model concerns market moods and second phase presents prior methods that apply a spatially weighted metric in stock market analysis. The third part of section three focused on the network dynamics of stock returns. Section four discusses the empirical application of the proposed model to the finance sector of New York Stock Exchange (NYSE). Finally, section five concludes.

\section{Theoretical background}

The primary tenets of capital markets theory, largely developed over the past 60 years, rests on a few key concepts, primarily efficient markets and investor rationality (Fama, 1970). The basis of these concepts is that the rational investors use the market for their own interests and unwittingly cause prices to reflect current information and analysis. From this perspective, the time evolutions of stock returns are well described as a random process (Fama, 1995). In capital markets theory, this random change implies that no one should be able to forecast a stock's return unless they incorporate measures of its riskiness, such as its beta. According to this view, the belief that herd behavior reflects the irrational response of investors rather than the outcome of rational decision making implies that prices may be driven away from their equilibrium values. Under this premise, investors are exposed to the unpredictable whims of herds and may be forced to transact at inefficient prices.

Large numbers of studies conducted by experimental economists and market psychologists have documented departures from efficient markets (Byun, Lim, \& Yun, 2016; Lawrence, McCabe, \& Prakash, 2007; Urquhart \& Hudson, 2013; Urquhart \& McGroarty, 2014): Variables with no apparent connection to risk are able to forecast stock returns, both in time series and cross-section analyses (Byun et al., 2016; Campbell \& Thompson, 2008; Cenesizoglu \& Timmermann, 2008; Guo \& Savickas, 2006; Lunde \& Timmermann, 2012). Many of these studies have been replicated in a variety of samples and are generally considered to be established facts (Lo, 2004)). However, it has not yet been determined whether cross-correlation behavior between stock price fluctuations has a similar universal nature (Pan \& Sinha, 2007).

1 Applied methods are the most common techniques for statistical data analysis and the primary task of exploratory data mining. They can contribute to the definition of a formal classification scheme or taxonomy by revealing associations and structure in data that were not previously evident. These methods avoid imposing any specific restrictions over the tested items. In fact, the only required data is a measure for determining associations. 
Preeminent scholars such as Herbert Simon, Daniel Kahneman, Richard Thaler, and Amos Tversky were among the first to study how individuals are systematically and predictably limited and occasionally "irrational" in their individual judgment and decisions (Lo, 2004). A growing body of evidence generated by decision science scholars demonstrates that investors' systematic judgment errors induced by their biological motivates result in stocks' divergence from randomness. According to this view, investors' motivational state may be shaped by many controlling stimuli such as the power of mass psychology, risk tolerance and misguided thinking (Engelberg \& Parsons, 2016; Nofsinger, 2016; Siganos, Vagenas-Nanos, \& Verwijmeren, 2017). In another word, it is believed that the physiological variables associated with the autonomic nervous system are highly correlated with market events, even for highly experienced traders. In the market ecology, such a correlation generates a complex mechanism of transmission of thoughts or behavior that leads to systemic instabilities.

\subsection{Stock market bipolar behavior}

In this section, we provide a detailed description of SBB and its implication in the behavioral economics and finance literature. Formerly known as, manic depression, bipolar disorder is a medical malfunctioning of brain mechanisms that manage individuals' moods. This condition causes serious shifts in mood, energy, thinking, and behavior that range from the highs of mania at one extreme (pole) to the lows of depression. As with many other mental illnesses, bipolar disorder has its own psychological features(Engelberg \& Parsons, 2016) and symptoms that are well described in many neuroscience and psychology textbooks (i.e., see (Belmaker, 2004)).

Initial implicit beliefs regarding the existence of market bipolar disorder may be found in the writings of John Maynard Keynes, who is one of the founding fathers of modern macroeconomics. Keynes gained deep insight into human psychology and how psychology affects macroeconomics through consumption, investment, employment, government and the interest rate. In (Keynes, 1937, 2006), Keynes reported the erratic nature of mass psychology and purported that investors cannot afford to disregard it. From this point of view, irrationalities should be studied by considering how people aggregate in the complex, longlasting, repetitive, and subtle environment of the market. In (Keynes, 2006) Keynes divided time into normal and abnormal episodes and states, "In abnormal times in particular, when the hypothesis of an indefinite continuance of the existing state of affairs is less plausible than usual, the market will be subject to waves of optimistic and pessimistic sentiment". Keynes claimed that the waves of optimism and pessimism make it difficult for investors to accommodate these opposite and extreme moods (Cheung, 2010). Addressing these difficulties, he advocated for government policy intervention to reduce the adverse effects of economic booms and recessions.

Later, in 1949, Benjamin Graham, the father of value investing and author of "The Intelligent Investor", explicitly argued that the stock market (which he coined "Mr. Market") suffers from bipolar disorder (Graham \& Zweig, 2003). In chapter 8, Graham asks the reader to imagine that he is one of two owners of a business, along with a partner called "Mr. Market". The partner frequently offers to sell his share of the business or to buy the reader's share. As the partner's estimate of the business value ranges from very pessimistic to wildly optimistic, which we label as bipolar behavior. Since the publication of this scenario by Graham, his view of "Mr. Market" has been cited numerous times to explain stock market fluctuations based on investors sentiment; (Baker \& Wurgler, 2006; Barberis, Shleifer, \& Vishny, 1998; Cheung, 2010; Greenwald, Kahn, Sonkin, \& Van Biema, 2004; Otuteye \& Siddiquee, 2015).

Despite the theoretical literature on the existence of the bipolar disorder at the market level, a rigorous quantitative framework has yet to be fully articulated. Current knowledge is more about a market's bipolar behavior showing extreme moods as poles of disorder distant from normal behavior. In our research detecting the poles of abnormal mood is only the first phase of diagnosing 'stocks' and market's bipolar disorder'. In the second step, we model the complex multi-state (normal, mania, depression and chaos $^{2}$ ) network structure and trace SBB from the self-organized dynamics of stock returns in response to the market changes. In

\footnotetext{
${ }^{2}$ Chaos mood is an important but somewhat missing concept in market state literature. The concept of market stress does not necessarily imply that the market as a whole should show either large negative or positive returns. Indeed, it can contain both large negative and positive returns at a certain point of time. In this case, the accumulated absolute return of each stock for time $t$ would be high but there would not be an imaginable direction for that. Defining market extreme mood as only arising when large positive or negative returns excludes this important market mood from market behavior analysis.
} 
the next section, we provide the precise mathematical process of deriving SBB in the body of suggested CEN model. Meanwhile, we establish the link between our knowledge of SBB in the finance literature with its network implications.

\section{Methodology and model}

According to (Baele, Ferrando, Hördahl, Krylova, \& Monnet, 2004), the financial behavior of stock markets may be assessed based on 1) price, 2) news and 3) quantity measures. In this study, we focus on, the price-based indicator of stocks' collective behavior. Our methodology articulates the emergence and dynamical process of stock return network which is embedded in the spatial properties of the ' $\mathrm{m}$ ' dimensional Euclidean space. We present a three-phase study scheme that initiates a market mood segmentation process (time specification). In the second phase, we show how we can portrait the spatial properties of the stock aggregate (space specification) in a two-dimensional graph. To this end, we use two established approaches (MDS and AHC) that basically translating $\left(\mathbb{R}^{\mathrm{m}}\right)$ into $\left(\mathbb{R}^{2}\right)$ spaces. Although such a translation contains errors (especially in visualizing bilateral distances), their application is very helpful in conceptualizing the basic model (CEN) embedded in $\left(\mathbb{R}^{\mathrm{m}}\right)$. In the empirical setting, we use these methods as an estimated visual proxy along with the numerical outputs of the CEN model. Finally, in the third phase, we present the suggested multi-state CEN structure and its dynamics in $\left(\mathbb{R}^{\mathrm{m}}\right)$ as the main purpose of this paper.

\subsection{Detecting market moods}

In the first phase of our methodology, we detect market moods by scaling the main data matrix into different market mood data sets. We let $R=\left(r_{t, i}\right) \in \mathbb{M}_{m, n}$ determine our data matrix with $T=\{1, \ldots \mathrm{m}\}$ rows and $V=\{1, \ldots \mathrm{n}\}$ columns. For $\mathrm{t} \in \mathrm{T}$ and $\mathrm{i} \in \mathrm{V}$, $r_{t, i}$ denote the logarithmic return of stock ' $i$ ' in a time interval $\Delta t$ and $\mathbb{M}_{m, n}$ denote the space of all $m \times n$ matrices. Matrix $R$ can be shown with the column vectors $R=\left[\overrightarrow{r_{1}} \ldots \ldots \overrightarrow{r_{n}}\right]$ and row vectors $R=\left[\begin{array}{llll}\overrightarrow{r_{1}} & \ldots & \ldots & \overrightarrow{r_{m}}\end{array}\right]$ in in an extended format as follows:

$$
\mathrm{R}=\left[\begin{array}{ccc}
\mathrm{r}_{1,1} & \cdots & \mathrm{r}_{1, \mathrm{n}} \\
\vdots & \ddots & \vdots \\
\mathrm{r}_{\mathrm{m}, 1} & \cdots & \mathrm{r}_{\mathrm{m}, \mathrm{n}}
\end{array}\right]
$$

In order to perform a market mood segmentation scheme, we first apply Eq. (1) to scale market time into normal and abnormal episodes using $\varepsilon_{t}$ which is the sum of the absolute return values of $n$ stocks in time $t \in T$ as follows:

$$
\varepsilon_{t}=\sum_{i=1}^{n}\left|\mathrm{r}_{\mathrm{t}, \mathrm{i}}\right|=\left\|\overrightarrow{\mathrm{r}}_{\mathrm{t}}\right\|_{1}
$$

Mathematically, $\varepsilon_{t}$ corresponds to the one-norm of the row vector $\overrightarrow{r_{t}} \in R$. We apply Eq. (1) for all $t=\{1, \ldots m\}$ and sort them in ascending order. The resulting $\mathrm{m} \times 1$ vector $\varepsilon_{\mathrm{t}}$ has a first element $\varepsilon_{1}$ corresponding to the time that market has the lowest aggregate return from ' $n$ ' stocks (regardless of the sign of return) and $\varepsilon_{m}$ will correspond to the time that the entire market has the highest positive or negative return compared with other days. Plotting $\varepsilon_{t}$ for a large ' $t^{\prime}$ sample shows that almost $90 \%$ of the $\varepsilon_{t}$ falls within (mean \pm standar deviation) interval on the left side of the curve with a very low ascending slope (i.e. see Fig. 2). We consider these dates as the normal times and the remaining (at the end tail of curve with a high ascending slope) as the abnormal times. Substitute method can be a binary clustering algorithm like K-means that divides $\varepsilon_{t}$ into two blocks of normal and abnormal times.

However, it is not necessary to use a statistical or clustering measure when using large samples since an error in the cut-off point would affect only a few marginal dates moving from one group to another. These marginal dates have similar features from both spaces and their inclusion would not affect the overall feature of each market mood. Our segmentation scheme will divide the data matrix $R$ into normal $R^{\tilde{n}}=\left(r_{t, i}^{\tilde{n}}\right) \in \mathbb{M}_{m^{\tilde{n}}, n^{\tilde{n}}}$ and abnormal $R^{a}=\left(r_{t, i}^{a}\right) \in M_{m^{a}, n^{a}}$ data sets where $R^{\tilde{n}}, R^{a} \subset R$ and $m=m^{\tilde{n}}+$ $\mathrm{m}^{\mathrm{a}}$. In the next step, we apply the second criteria $\partial_{\mathrm{t}}$ and scale $\mathrm{R}^{\mathrm{a}}$ into three different episodes (mania ' $\mathrm{m}^{\prime}$, chaos 'ç' and depression ' $\left.\mathrm{d}^{\prime}\right)$. We let $\mathrm{a}=\{\mathrm{m}, \mathrm{c}, \mathrm{d}\} \subset \theta$ and $\theta=\{\tilde{\mathrm{n}}, \mathrm{m}, \mathrm{c}, \mathrm{d}\}$ denote all market moods. In Eq. (2) we formulize $\partial_{\mathrm{t}}$ as the sum of the return values from ' $\mathrm{n}^{\mathrm{a} \prime}$ stocks at time $\mathrm{t} \in \mathrm{T}^{\mathrm{a}}$ as follows: 


$$
\partial_{\mathrm{t}}=\sum_{\mathrm{i}=1}^{\mathrm{n}^{\mathrm{a}}} \mathrm{r}_{\mathrm{t}, \mathrm{i}}^{\mathrm{a}}
$$

Applying Eq. (2) for each $t=\left\{1 \ldots \mathrm{m}^{\mathrm{a}}\right\}$ abnormal times and sorting them in ascending order gives us the $\partial_{\mathrm{t}}$ as a $\mathrm{m}^{\mathrm{a}} \times 1$ vector. We plot $\partial_{\mathrm{t}}$ (i.e. see Fig. 2 (b)) and classify abnormal times into different sub categories: 1) times with high negative aggregate return move in the left side of the $\partial_{t}$ curve as noted by a high upward slope concave to vector ' $t$ ' (depression mood), 2) times with high chaos aggregate returns as noted by a low upward slope in the middle of the curve (chaos mood) and finally 3 ) times with high positive aggregate returns as noted by a high upward slope in the last part of the figure, convex to vector ' $\mathrm{t}$ ' (mania mood). With this classification scheme, we divide the abnormal data matrix $\mathrm{R}^{\mathrm{a}}$ into mania $\mathrm{R}^{\mathrm{m}}$, chaos $\mathrm{R}^{\mathrm{c}}$ and depression $\mathrm{R}^{\mathrm{d}}$ data matrices. At the end of this phase, we have the set of data matrixes with each element corresponding to each market mood and $R^{\theta}=$ $\left\{\mathrm{R}^{\tilde{n}}, \mathrm{R}^{\mathrm{m}}, \mathrm{R}^{\mathrm{c}}, \mathrm{R}^{\mathrm{d}}\right\}$ or in an extended format as follows:

$$
\mathrm{R}^{\theta}=\left[\begin{array}{ccc}
\mathrm{r}_{1,1}^{\theta} & \cdots & \mathrm{r}_{1, \mathrm{n}^{\theta}} \\
\vdots & \ddots & \vdots \\
\mathrm{r}_{\mathrm{m}^{\theta}, 1}^{\theta} & \cdots & \mathrm{r}_{\mathrm{m}^{\theta}, \mathrm{n}^{\theta}}^{\theta}
\end{array}\right]
$$

In the next phase, we use these data sets and present the spatial representation of stock return using AHC and MDS methods.

\subsection{Network configuration in the two dimensional spaces}

In this section, we briefly present the application of MDS and AHC methods for estimating the two-dimensional representation of stock returns from ' $m$ 'dimensional space. These methods served as a 'two dimensional' proxy of the basic CEN model in $\mathrm{R}^{\mathrm{m}}$. Generally speaking, MDS techniques develop spatial representations of psychological stimuli or other complex objects based on judgments (e.g., preference, (dis)similarity)(D. Carroll \& M. Wish, 1975; J. D. CARROLL \& M. WISH, 1975). Using this method, the objects are represented as points in a map such that a small distance between two points corresponds to the increased similarity between two objects and a large distance corresponds to reduced similarity (see, e.g., Fig. 3). Researchers define MDS using three processes: 1) selecting the objects that will be analyzed, 2) deciding whether similarities or preferences are to be analyzed and, finally, 3) determining whether the analysis will be performed at the group or individual level. In this study, we aim to analyze stocks' (dis)similarity (time-varying synchronization in stock returns) at both the group and individual levels.

In most multidimensional scaling approaches, a measure of (dis)similarity between two objects selected from the same feature space is essential. We use the most popular metric for continuous features, the Euclidean distance, to formalize the spatial representation of return co-movement between $\mathrm{i}, \mathrm{j} \in \mathrm{V}$ pair stocks. Conceptually, the Euclidean distance is the length of the shortest line that connects $i$ and $j$ stocks with converting their multidimensional space into pairwise distances. Mathematically, it is the function $d: \mathbb{R}^{m} \times \mathbb{R}^{m} \rightarrow \mathbb{R}$ that assigns to any two vectors $\overrightarrow{\mathrm{r}}_{\mathrm{i}}, \overrightarrow{\mathrm{r}}_{\mathrm{j}} \in \mathrm{R}$ and determines the standard distance between them. Eq. (3) shows the Euclidean distance between stock $i$ and stock ' $j$ ' in ' $m$ ' dimensional space as follows:

$$
d(i, j)=\left\|\vec{r}_{1}-\vec{r}_{j}\right\|_{2}=\left(\sum_{t}\left(r_{t, i}-r_{t, j}\right)^{2}\right)^{\frac{1}{2}}
$$

Applying Eq. (3) over ' $n$ ' stocks in a data matrix gives $n(n-1) / 2$ possible pairwise distances which can be shown with a spatially weighted distance matrix $\mathrm{D}=\left(\mathrm{d}_{\mathrm{i}, \mathrm{j}}\right) \in \mathbb{M}_{\mathrm{n}, \mathrm{n}}$. We apply Eq. (3) over each data set corresponding to each market mood and determine each distance matrix. We let $D^{\theta}=\left\{D^{\tilde{n}}, D^{m}, D^{c}, D^{d}\right\}$ define our distance matrices and show it in extended format as follows:

$$
\mathrm{D}^{\theta}=\left[\begin{array}{ccc}
\mathrm{d}_{1,1}^{\theta} & \cdots & \mathrm{d}_{1, \mathrm{n}^{\theta}} \\
\vdots & \ddots & \vdots \\
\mathrm{d}_{\mathrm{n}^{\theta}, 1}^{\theta} & \cdots & \mathrm{d}_{\mathrm{n}^{\theta}, \mathrm{n}^{\theta}}^{\theta}
\end{array}\right]
$$


Having $\mathrm{D}^{\theta}$, we can map out the original high dimensional space to a lower space, but do so in an attempt to preserve pairwise distances. In practice, given a distance matrix $\mathrm{D}, \mathrm{MDS}$ attempts to find ' $\mathrm{n}$ ' data points in low dimensions with coordinates corresponding to $\mathrm{d}_{\mathrm{i}, \mathrm{j}}$ that minimizes the following function:

$$
\min \sum_{i} \sum_{j}\left(d_{i, j}-d^{\prime}{ }_{i, j}\right)
$$

In the next step, we apply AHC which is an additional step over distance matrices to determine stock-cluster of stocks associations in and ordered and more understandable platform.

\subsubsection{Agglomerative hierarchical cluster analysis}

Given a set of data R, the typical goal of partitional clustering is to form a k-block set partition $\Pi_{\mathrm{k}}$ of the data. In this study, we use AHC, a widely used method of building a cluster hierarchy, to study (dis)similarities among stocks collective behavior. Technically, AHC initializes a cluster system as a set of single clusters (agglomerative case) or a single cluster of all objects (divisive case). It proceeds iteratively, merging or splitting the most similar cluster(s) until the stop criterion is achieved. To merge or split clusters of objects, rather than individual objects, the distance between individual objects must be generalized to the distance between clusters. Such a derived proximity measure is known as a linkage metric. Major inter-cluster linkage metrics include single link, average link, and complete link. In this study, we use the average link metric. Mathematically the average linkage function is given by the following expression:

$$
d\left((\delta)_{i, j}\right)=\frac{1}{n_{(\delta)_{i}} \times n_{(\delta)_{j}}} \sum_{i=1}^{n_{i}} \sum_{j=1}^{n_{(\delta)_{j}}} d(i, j) ;
$$

where:

$\mathrm{d}(\mathrm{i}, \mathrm{j})$ is the distance between objects $\mathrm{i} \in(\delta)_{\mathrm{i}}$ and $\mathrm{j} \in(\delta)_{\mathrm{j}}$;

$(\delta)_{\mathrm{i}}$ and $(\delta)_{\mathrm{j}}$ are two sets of objects (clusters); and

$\mathrm{n}_{(\delta)_{\mathrm{i}}}$ and $\mathrm{n}_{(\delta)_{\mathrm{j}}}$ are the numbers of objects for subsets $(\delta)_{\mathrm{i}}$ and $(\delta)_{\mathrm{j}}$ respectively.

Using the average linkage metric $\mathrm{d}\left((\delta)_{\mathrm{i}, \mathrm{j}}\right)$, we build a cluster hierarchy or Dendrogram. In this manner, we identify (dis)similar stocks from the (right) left of the dendrogram with (long) short vertical lines and trace 1$) n(n-1) / 2$ bilateral (stock-stock) and 2) $\sum_{K=2}^{n} \frac{n !}{n !}$ multilateral (stock-cluster) (dis)similarity among the aggregation of ' $n$ ' stocks. The ultimate number of imaginable (dis)similarity $\Psi_{\mathrm{n}}$ (both stock-stock and stock-cluster distances) can be determined by Eq. (6) as follows:

$$
\Psi_{\mathrm{n}}=\mathrm{n}(\mathrm{n}-1) / 2+\sum_{\mathrm{K}=2}^{\mathrm{n}-1} \frac{\mathrm{n} !}{\mathrm{K} !} \quad \text { where } \mathrm{n}>2
$$

\subsection{The multi-state complete Euclidean network model}

In this section, we present the multi-state CEN model of stock return using the graph theory which is the natural framework for the accurate mathematical handling of complex networks. By definition, a graph is a pair $G=(\mathrm{V}, \mathrm{E})$ of sets satisfying $\mathrm{E} \subseteq[\mathrm{V}]^{2}$; thus the elements of $E$ are 2-element subsets of $V$. To avoid notational ambiguities, we assume that $V \cap E=\emptyset$. The elements of $V$ are the nodes (vertices) of the graph $G$ and the elements of $E$ are its edges (lines), where the edges connect pairs of nodes $(i, j) \in$ $E$ (with $i, j \in V$ ). By this definition, the stocks graph $G_{n, k}$ can be characterized by the number of nodes ' $n$ ' denoting the stocks traded in the market and $\mathrm{K}=\mathrm{n}(\mathrm{n}-1) / 2$ edges denoting possible pairwise (dis)similarity in the movement of stock return. 
Connecting all firms to each other constitutes a complete Euclidean network ${ }^{3}$ where the loci of nodes are given in the Euclidean ' $\mathrm{m}^{\prime}$ dimensional space. In such a complete network structure, each node (stock) has a degree $\mathrm{n}-1$ and the $\mathrm{n} \times \mathrm{n}$ symmetric distance matrix ' $\mathrm{L}$ ' describes the graph with elements $l_{i, j}$ equal to the weights of existing edges calculated in ' $\mathrm{m}$ ' dimensional space (Eq. (7)). Similar to other Euclidean networks, the proposed financial network satisfies two important properties that do not necessarily hold for general edge weighted network. First, the distances satisfy the triangle inequality: The distance from ' $\mathrm{i}$ ' to ' $\mathrm{j}$ ' is never greater than the distance from ' $\mathrm{i}$ 'to ' $\mathrm{x}$ ' plus the distance from ' $\mathrm{x}$ ' $\mathrm{to}$ ' $\mathrm{j}$ '. Second, vertex positions give a lower bound on path length: No path from ' $i$ ' to ' $j$ ' will be shorter than the distance from ' $i{ }^{\prime}$ to ' $j$ '.

As like the procedure described in section 3.1, we can scale our data matrix into four featured data sets $R^{\theta}$ and apply Eq. (7) to calculate the set of edge length sets represented by $L^{\theta}=\left\{L^{\tilde{n}}, L^{m}, L^{c}, L^{d}\right\}$.

$$
l_{\mathrm{i}, \mathrm{j}}^{\theta}=\left\|\frac{\overrightarrow{\mathrm{r}_{1}^{\theta}}-\overrightarrow{\mathrm{r}_{\mathrm{j}}^{\theta}}}{\mathrm{m}^{\theta}}\right\|_{2}=\left(\frac{\sum_{\mathrm{t}}\left(\mathrm{r}_{\mathrm{t}, \mathrm{i}}^{\theta}-\mathrm{r}_{\mathrm{t}, \mathrm{j}}^{\theta}\right)^{2}}{\mathrm{~m}^{\theta}}\right)^{\frac{1}{2}}
$$

Having $L^{\theta}$ enables us to articulate the multi-state CEN model denoted by $G_{n^{\theta}, k^{\theta}}^{\theta}$. In the Fig. 1 , we simplify all the steps required to articulate the multi-state network structure and trace its state dependent dynamics. This process is defined in a way that one can easily trace the derivation of all equations with respect to each other.

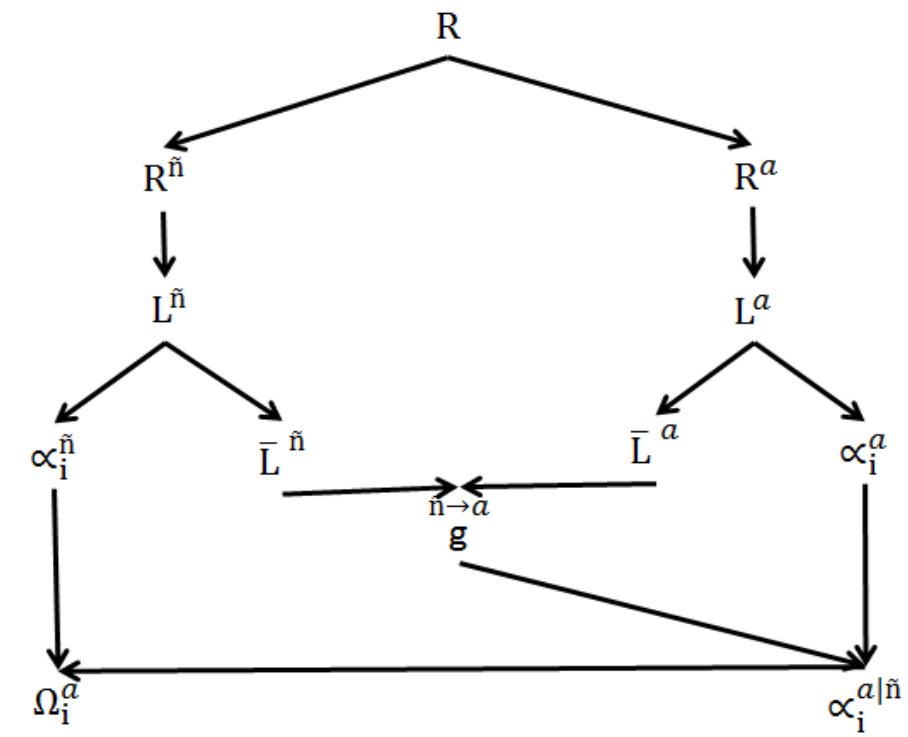

Figure 1. CEN model In this figure, we simplify all the steps and chain of equations required to articulate the multi-state CEN structure and its dynamics. This process starts from the data and leads to the SBB.

\subsubsection{The alpha measure and network dispersion}

There are several network measures describing the structure of complex networks but essentially they fall into two major categories: 1) measures that report the behavior of each node within aggregate (micro results) 2) measures that describe properties of the aggregate (macro results). In this section, we introduce the alpha measure which basically reports the spatial difference in the loci of each individual stock from the aggregate (micro-measure). In the network terminology, it corresponds to the closeness centrality measure of a CEN with the edges weighted by log return (dis)similarity. Mathematically, the alpha

\footnotetext{
${ }^{3}$ The Euclidean networks are networks whose vertices are points in the plane and whose edge weights are defined by the geometric distances between the points.
} 
measure is the average of all edge lengths that are connected to stock ' $\mathrm{i}$ ' in the ' $\theta^{\prime}$ market mood. Thus, a small alpha corresponds to a more central stock with more similar return pattern with the aggregate of ' $n$ ' stocks and vice versa.

$$
\propto_{\mathrm{i}}^{\theta}=\frac{\sum_{\mathrm{j}} l_{\mathrm{i}, \mathrm{j}}^{\theta}}{\mathrm{n}^{\theta}-1} \quad \text { (8) } \quad \text { or in an extended format } \quad \propto_{\mathrm{i}}^{\theta}=\frac{\sum_{\mathrm{j}}\left(\frac{\sum_{\mathrm{t}}\left(\mathrm{r}_{\mathrm{t}, \mathrm{i}}^{\theta}-\mathrm{r}_{\mathrm{t}, \mathrm{j}}^{\theta}\right)^{2}}{\mathrm{~m}^{\theta}}\right)^{\frac{1}{2}}}{\mathrm{n}^{\theta}-1} \quad(8-1)
$$

Applying Eq. (8) over each edge length matrix will result in the set of closeness centrality sets $\propto^{\theta}=\left\{\propto^{\tilde{n}}, \propto^{\mathrm{m}}, \propto^{\mathrm{c}}, \propto^{\mathrm{d}}\right\}$. Having this measure we can understand the (dis)similarity in the return movement of each stock with market aggregate in different market moods. This stage of knowledge questions the scale of change in alpha measure by market transition from normal to abnormal moods. We answer to this question in Sec. 3.3.2. In the next step, we introduce the network dispersion measure $\overline{\mathrm{L}}^{\theta}$ which reports to how extend return patterns of the network is (dis)similar as a whole. Unlike the alpha measure $\bar{L}^{\theta}$ is a measure of market mood (macro behavior). Mathematically, we can derive it from the average of all edge lengths in one network state as follows:

$$
\begin{aligned}
& \overline{\mathrm{L}}^{\theta}=\frac{\sum_{\mathrm{i}} \sum_{\mathrm{j}} l_{\mathrm{i}, \mathrm{j}}^{\theta}}{\mathrm{K}^{\theta}} \text { where for } \mathrm{K}^{\theta}=\frac{\mathrm{n}^{\theta}\left(\mathrm{n}^{\theta}-1\right)}{2} \Rightarrow \overline{\mathrm{L}}^{\theta}=\frac{2 \sum_{\mathrm{i}} \sum_{\mathrm{j}} l_{\mathrm{i}, \mathrm{j}}^{\theta}}{\mathrm{n}^{\theta}\left(\mathrm{n}^{\theta}-1\right)} \\
& \text { (7), (9) } \Rightarrow \overline{\mathrm{L}}^{\theta}=\frac{2 \sum_{\mathrm{i}} \sum_{\mathrm{j}}\left(\frac{\sum_{\mathrm{t}}\left(\mathrm{r}_{\mathrm{t}, \mathrm{i}}^{\theta}-\mathrm{r}_{\mathrm{t}, \mathrm{j}}^{\theta}\right)^{2}}{\mathrm{~m}^{\theta}}\right)^{\frac{1}{2}}}{\mathrm{n}^{\theta}\left(\mathrm{n}^{\theta}-1\right)} \quad(9-1)
\end{aligned}
$$

Comparing the $\overline{\mathrm{L}}^{\theta}$ among different network states shows in which state network as a whole compacted or dispersed compared to other states. In the stock market context, this measure reports the degree of herding or dispersion of market during different market moods.

\subsubsection{Network dynamics of stock return: global and self-organized}

Assuming the given multi-state CEN structure, we can identify the scale and direction of change in the loci of each node that is observed by market transition from normal to abnormal moods. Such a dynamical process can be quantified with two different parameters. 1) The global dynamics which report the scale and direction of change in the alpha measure under a common scale factor denoted by $\stackrel{\tilde{n} \rightarrow a}{g}$ as follows:

$$
\stackrel{\tilde{\mathrm{n}} \rightarrow \mathrm{a}}{\mathrm{g}}=\frac{\overline{\mathrm{L}}^{\mathrm{a}}}{\overline{\mathrm{L}}^{\tilde{n}}}
$$

In appendix $A$ and $B$, we derive $\stackrel{\tilde{n} \rightarrow \mathrm{a}}{\mathrm{g}}$ with respect to both edge length and data elements as represented in Eq. (10-1) and (10-2) respectively:

$$
\stackrel{\tilde{n} \rightarrow \mathrm{a}}{\mathrm{g}}=\frac{\mathrm{n}^{\tilde{n}}\left(\mathrm{n}^{\tilde{n}}-1\right) \sum_{\mathrm{i}} \sum_{\mathrm{j}} l_{\mathrm{i}, \mathrm{j}}^{\mathrm{a}}}{\mathrm{n}^{\mathrm{a}}\left(\mathrm{n}^{\mathrm{a}}-1\right) \sum_{\mathrm{i}} \sum_{\mathrm{j}} l_{\mathrm{i}, \mathrm{j}}^{\tilde{n}}} \quad(10-1)
$$

$$
\stackrel{\tilde{n} \rightarrow a}{g}=\frac{n^{\tilde{n}}\left(n^{\tilde{n}}-1\right)\left(\sum_{i} \sum_{j}\left(m^{\tilde{n}} \sum_{t}\left(r_{t, i}^{a}-r_{t, j}^{a}\right)^{2}\right)^{\frac{1}{2}}\right)}{n^{a}\left(n^{a}-1\right)\left(\sum_{i} \sum_{j}\left(m^{a} \sum_{t}\left(r_{t, i}^{\tilde{n}}-r_{t, j}^{\tilde{n}}\right)^{2}\right)^{\frac{1}{2}}\right)}
$$

Under such transformation, the global dynamics of the network denoted by $\Delta \mathrm{g}$ would be equal to the average edge length of an abnormal state network $\bar{L}^{\mathrm{a}}$ minus its normal component $\overline{\mathrm{L}}^{\tilde{n}}$.

$$
\stackrel{\tilde{\mathrm{n}} \rightarrow \mathrm{a}}{\Delta \mathrm{g}}=\overline{\mathrm{L}}^{\mathrm{a}}-\overline{\mathrm{L}}^{\tilde{\mathrm{n}}} \quad(10-3)
$$


In this paper, we do not explore the global dynamics in micro level. However, for further exploration, it is possible to calculate the global dynamics of edge length or alpha measure during different abnormal market moods.

2) The second parameter $S B B$ reflects the heterogeneous response of traders to the changing market condition. In order to calculate the SBB, first we need to exclude the effect of global dynamics from the alpha measure of each stock. We do this by multiplying the alpha measure of the abnormal states with the inverse of global dynamics scalar $\stackrel{\tilde{n} \rightarrow a}{g}$ as follows:

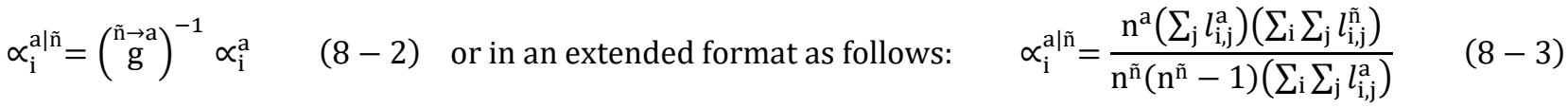

$$
\begin{aligned}
& \alpha_{i}^{a} \mid \tilde{n}=\frac{n^{a}\left(\sum_{i} \sum_{j}\left(\sum_{t}\left(r_{t, i}^{\tilde{n}}-r_{t, j}^{\tilde{n}}\right)^{2}\right)^{\frac{1}{2}}\right)\left(\sum_{j}\left(\sum_{t}\left(r_{t, i}^{a}-r_{t, j}^{a}\right)^{2}\right)^{\frac{1}{2}}\right)}{n^{\tilde{n}}\left(n^{\tilde{n}}-1\right)\left(\sum_{i} \sum_{j}\left(m^{\tilde{n}} \sum_{t}\left(r_{t, i}^{a}-r_{t, j}^{a}\right)^{2}\right)^{\frac{1}{2}}\right)}
\end{aligned}
$$

The resulting transformed alpha measure $\propto_{i}^{\mathrm{a} \mid \tilde{n}}$ must basically be equal to its normal component $\propto_{i}^{\tilde{n}}$. However, according to the theory discussed in section 2, investors can react in different ways to the changing market condition which in turn results in a heterogeneous (self-organized) dynamics of stock return different (higher or lower) than the global dynamics. In Eq. (11), we model such erratic dynamics for each individual stock during each abnormal market mood as evidence of SBB:

$$
\Omega_{\mathrm{i}}^{\mathrm{a}}=\propto_{\mathrm{i}}^{\mathrm{a} \mid \tilde{n}}-\propto_{\mathrm{i}}^{\tilde{n}} \quad(11) \quad \text { where } \quad \sum_{\mathrm{i}} \Omega_{\mathrm{i}}^{\mathrm{a}}=0
$$

As like extension described for the transformed alpha measure, SBB function can be derived based on the edge length or data elements. In appendix A and B, we derive these equations and report the results in Eq. $(11-1)$ and Eq. $(11-2)$ as follows:

$$
\begin{aligned}
& \Omega_{\mathrm{i}}^{\mathrm{a}}=\frac{\mathrm{n}^{\mathrm{a}}\left(\sum_{\mathrm{j}} l_{\mathrm{i}, \mathrm{j}}^{\mathrm{a}}\right)\left(\sum_{\mathrm{i}} \sum_{\mathrm{j}} l_{\mathrm{i}, \mathrm{j}}^{\tilde{\mathrm{n}}}\right)-\mathrm{n}^{\tilde{\mathrm{n}}}\left(\sum_{\mathrm{j}} l_{\mathrm{i}, \mathrm{j}}^{\tilde{\mathrm{n}}}\right)\left(\sum_{\mathrm{i}} \sum_{\mathrm{j}} l_{\mathrm{i}, \mathrm{j}}^{\mathrm{a}}\right)}{\mathrm{n}^{\tilde{n}}\left(\mathrm{n}^{\tilde{n}}-1\right)\left(\sum_{\mathrm{i}} \sum_{\mathrm{j}} l_{\mathrm{i}, \mathrm{j}}^{\mathrm{a}}\right)} \quad(11-1) \\
& \Omega_{\mathrm{i}}^{\mathrm{a}}=\frac{\left(\mathrm{n}^{\mathrm{a}}\left(\sum_{\mathrm{i}} \sum_{\mathrm{j}}\left(\sum_{\mathrm{t}}\left(\mathrm{r}_{\mathrm{t}, \mathrm{i}}^{\tilde{n}}-\mathrm{r}_{\mathrm{t}, \mathrm{j}}^{\tilde{n}}\right)^{2}\right)^{\frac{1}{2}}\right)\left(\sum_{\mathrm{j}}\left(\sum_{\mathrm{t}}\left(\mathrm{r}_{\mathrm{t}, \mathrm{i}}^{\mathrm{a}}-\mathrm{r}_{\mathrm{t}, \mathrm{j}}^{\mathrm{a}}\right)^{2}\right)^{\frac{1}{2}}\right)\right)-\left(\mathrm{n}^{\tilde{\mathrm{n}}}\left(\sum_{\mathrm{j}}\left(\sum_{\mathrm{t}}\left(\mathrm{r}_{\mathrm{t}, \mathrm{i}}^{\tilde{n}}-\mathrm{r}_{\mathrm{t}, \mathrm{j}}^{\tilde{\mathrm{n}}}\right)^{2}\right)^{\frac{1}{2}}\right)\left(\sum_{\mathrm{i}} \sum_{\mathrm{j}}\left(\sum_{\mathrm{t}}\left(\mathrm{r}_{\mathrm{t}, \mathrm{i}}^{\mathrm{a}}-\mathrm{r}_{\mathrm{t}, \mathrm{j}}^{\mathrm{a}}\right)^{2}\right)^{\frac{1}{2}}\right)\right)}{\mathrm{n}^{\tilde{\mathrm{n}}}\left(\mathrm{n}^{\tilde{\mathrm{n}}}-1\right)\left(\sum_{\mathrm{i}} \sum_{\mathrm{j}}\left(\mathrm{m}^{\tilde{\mathrm{n}}} \sum_{\mathrm{t}}\left(\mathrm{r}_{\mathrm{t}, \mathrm{i}}^{\mathrm{a}}-\mathrm{r}_{\mathrm{t}, \mathrm{j}}^{\mathrm{a}}\right)^{2}\right)^{\frac{1}{2}}\right)}
\end{aligned}
$$

$(11-2)$

The output of this model can take negative, positive or zero values so that the sum of SBB for all stocks in an abnormal market mood must be zero. Ideally, the SBB of each stock must be zero which describes a stock with the same aggregate behavior (regardless if it is an integrated or a segmented stock) before and after market change to abnormal moods. In the network context, zero SBB of a stock implies that its transformed closeness centrality (alpha measure) is state invariant. On the other hand, any observed self- organized dynamics (SBB) for each stock can be regarded as a heterogeneous response to the market change. In such case, the higher negative and positive SBB correspond to the stocks with considerable change in their network behavior during market transition to abnormal moods.

If the SBB of a stock is high and positive, it implies that the stock ' $i$ ' is generally integrated with the market, but change to a stock with segmented return behavior in abnormal states. We define and interpret this disorder as evidence of a divergent bipolar behavior. On the other hand, high negative SBB corresponds to the stocks where in usual times have returns which move differently from the market (a segmented pattern) and change nature to become integrated with aggregate market returns while transitioning to abnormal market moods. We define and interpret this acentric behavior as evidence of stock's convergent bipolar 
behavior. Finally, to calculate MBB of each abnormal market mood we average the absolute value of SBB in an abnormal state. We sum MBB of each state as the total MBB denoted by $\Omega$ as follows:

$$
\Omega^{\mathrm{a}}=\frac{1}{\mathrm{n}^{\mathrm{a}}} \sum_{i}\left|\Omega_{\mathrm{i}}^{\mathrm{a}}\right| \quad(11-3) \quad \Omega=\frac{1}{\mathrm{n}^{\mathrm{a}}} \sum_{a}\left|\Omega_{\mathrm{i}}^{\mathrm{a}}\right|=\frac{1}{\mathrm{n}^{\mathrm{m}}} \sum_{i}\left|\Omega_{\mathrm{i}}^{\mathrm{m}}\right|+\frac{1}{\mathrm{n}^{\mathrm{c}}} \sum_{i}\left|\Omega_{\mathrm{i}}^{\mathrm{c}}\right|+\frac{1}{\mathrm{n}^{\mathrm{d}}} \sum_{i}\left|\Omega_{\mathrm{i}}^{\mathrm{d}}\right| \quad(11-4)
$$

\section{Empirical results}

We investigate the empirical application of the suggested CEN model over $V=\{1, \ldots 80\}$ firms' stock from finance industry sector of the NYSE. The dataset consists of firms whose stock was traded during the entire study period from Jan 4, 2000 to Mar 18, 2016, excluding 344 days where at least one stock's return is not in the range of $-25 \%$ and $25 \%$. Our sample consists of $t=$ $\{1, \ldots .3735\}$ daily close log return observations for each selected stock. $\mathrm{R}=\left(\mathrm{r}_{\mathrm{t}, \mathrm{i}}\right) \in \mathrm{M}_{3735,80}$ denotes the primary data matrix with $r_{t, i}$ coordinates. We show our data matrix with $R=r_{i}=\left[r_{1} \ldots . r_{80}\right]$ column vectors and $R=r_{t}=\left[r_{1} \ldots . . r_{3735}\right]$ row vectors or in an extended format as follows:

$$
\mathrm{R}=\left[\begin{array}{ccc}
\mathrm{r}_{1,1} & \cdots & \mathrm{r}_{1,80} \\
\vdots & \ddots & \vdots \\
\mathrm{r}_{3735,1} & \cdots & \mathrm{r}_{3735,80}
\end{array}\right]
$$

We start our empirical analysis with suggested market mood specification procedure. We scale market time into normal and abnormal episodes by applying Eq. (1) for all $t=\{1, \ldots .3735\}$ days and derive the $\varepsilon_{t}$ as a $m \times 1$ vector. Sorting $\varepsilon_{t}$ in ascending and plot in Fig. 2 panel (a) shows that almost $90 \%$ of the times have a long low rising slope at the left part of the distribution and indicate the range of normal return moves. The right tail with a sharp increasing slope corresponds to around $10 \%$ of the days which correspond to abnormal days. We use the procedure discussed in section 3.1 to apply the cut-off point $a=3398$ and divide $\mathrm{R}$ into normal and abnormal matrices as follows:

$$
\mathrm{R}^{\tilde{\mathrm{n}}}=\left(\mathrm{r}_{\mathrm{t}, \mathrm{i}}^{\tilde{\mathrm{n}}}\right) \in \mathbb{M}_{3398,80}=\left[\begin{array}{ccc}
\mathrm{r}_{1,1} & \cdots & \mathrm{r}_{1,80} \\
\vdots & \ddots & \vdots \\
\mathrm{r}_{3398,1} & \cdots & \mathrm{r}_{3398,80}
\end{array}\right] \text { and } \mathrm{R}^{\mathrm{a}}=\left(\mathrm{r}_{\mathrm{t}, \mathrm{i}}^{\mathrm{a}}\right) \in \mathbb{M}_{337,80}=\left[\begin{array}{ccc}
\mathrm{r}_{1,1} & \cdots & \mathrm{r}_{1,80} \\
\vdots & \ddots & \vdots \\
\mathrm{r}_{337,1} & \cdots & \mathrm{r}_{337,80}
\end{array}\right]
$$
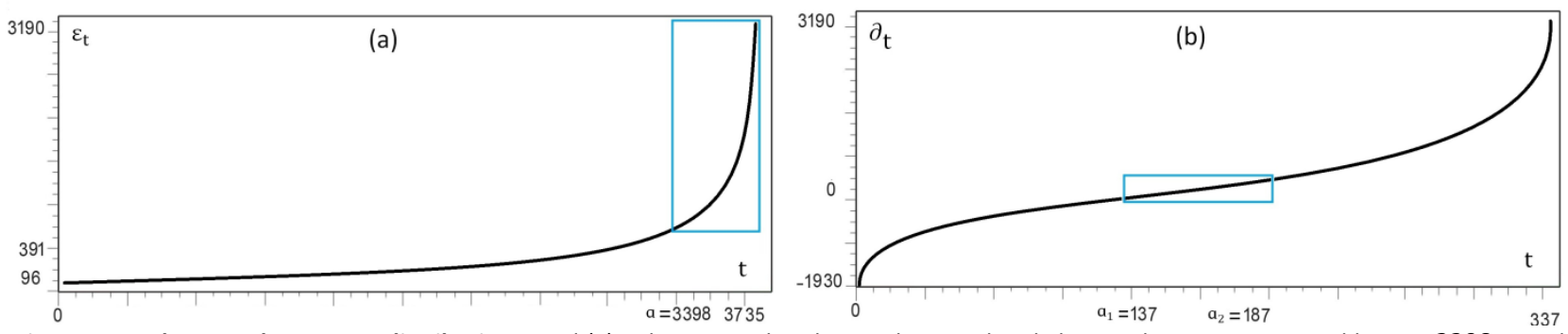

Figure 2. Market mood measures distribution Panel (a) indicates market days with normal and abnormal returns separated by a $=3398$. Panel

(b) indicates 1) market days with extreme negative return in $t<137$ with a high downward tail (depression mood), 2) market days with extreme chaos return where $137<\mathrm{t}<187$ (chaos mood) and 3) market days with extreme chaos return where $\mathrm{t}>187$ (mania mood).

In the next step, we apply the second criteria $\partial_{\mathrm{t}}$, the market abnormal mood measure to scale $\mathrm{R}^{\mathrm{a}}$ into the three different datasets $\mathrm{R}^{\mathrm{m}}, \mathrm{R}^{\mathrm{c}}, \mathrm{R}^{\mathrm{d}} \subset \mathrm{R}^{\mathrm{a}}$ representing mania, chaos and depression market moods respectively. We calculate $\partial_{\mathrm{t}}$ in all $\mathrm{t}=$ $\{1, \ldots 337\}$ abnormal days and visualize its ascending distribution in Fig. 2 panel (b). We apply $a_{1}=137$ cut point to split days with high negative return on the left side of the curve noted by a high upward slope concave to ' $t$ ' vector. On the other hand, $a_{2}=187$ splits the days with high positive return at the end of the curve convex to the vector ' $\mathrm{t}$ '. As a result, we obtain the depression and mania market mood data sets represented by $\mathrm{R}^{\mathrm{d}}$ and $\mathrm{R}^{\mathrm{m}}$ respectively. Market days with extreme chaos mood can be noted by a low upward slope in the middle of the curve which corresponds to the remaining days given by $R^{c}$. We show $R^{d}, R^{c}$ and $R^{m}$ as follows:

$$
\mathrm{R}^{\mathrm{d}}=\left(\mathrm{r}_{\mathrm{t}, \mathrm{i}}^{\mathrm{d}}\right) \in \mathbb{M}_{137,80} \quad \mathrm{R}^{\mathrm{c}}=\left(\mathrm{r}_{\mathrm{t}, \mathrm{i}}^{\mathrm{c}}\right) \in \mathbb{M}_{50,80} \quad \mathrm{R}^{\mathrm{m}}=\left(\mathrm{r}_{\mathrm{t}, \mathrm{i}}^{\mathrm{m}}\right) \in \mathbb{M}_{150,80}
$$




\subsection{Results from MDS and AHC}

In the second phase, we use each market mood datasets $R^{\theta}=\left\{R^{\tilde{n}}, R^{m}, R^{c}, R^{d}\right\}$ and ascertain the spatial weight of multilateral (dis)similarities from 'stock-stock' and 'stock-cluster of stocks' relations. Applying Eq. (3) over $\mathrm{i}, \mathrm{j} \in \mathrm{V}=\{1, \ldots, 80\}$ stocks will result in $80(80-1) / 2=3160$ possible pairwise spatial difference in the return movement of each datasets. These results articulate the network structure in each market mood. We show them with the distance weighted matrices $D^{\theta}=\left(d^{\theta}{ }_{i, j}\right) \in$ $\mathbb{M}_{80,80}$. Solving Eq. (4) for each distance matrix $D^{\theta}=\left\{D^{\tilde{n}}, D^{m}, D^{c}, D^{d}\right\}$ will enable us to derive $D^{\prime \theta}$ and portrait the spatial differences in a two dimensional space as given by Fig. 3.

In the Fig. 3, we highlight four example stocks where each shows a particular network transformation during different market moods. We interpret the behavior of sample stocks SCNB, PNC, FII and BAP and highlight them with red, green, orange and blue, respectively. In all four panels, the blue lines intersection point corresponds to the center of aggregate stocks so that a stock close to the intersection has a strong synchronized return movement with the common trend of the market aggregation.

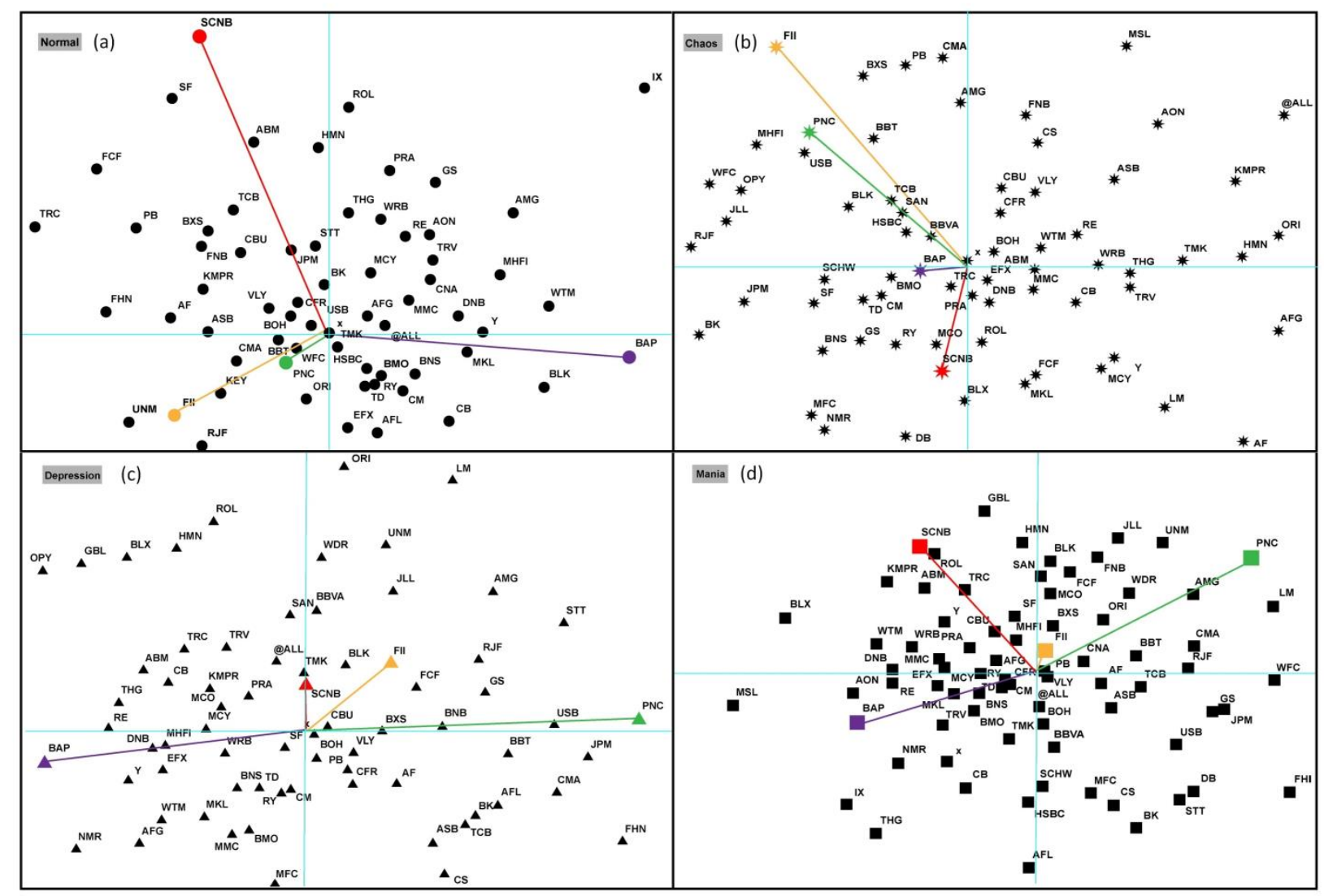

Figure 3. Stocks collective (dis)similarity pattern during each market mood. In this figure, we present the estimated spatial (dis)similarity patterns of each stock during each market mood. We colored four example stocks with distinguished changing return patterns. In each panel, the big and small distance from the blue cross section accounts for a low and high similarity between stock and the entire market respectively.

In the Panel (a), SCNB displays a highly segmented return pattern which has changed to a very synchronous pattern with market in the Panel (c). As described in section 3, this implies that the stock SCNB shows a convergent bipolar behavior during market transition to extreme negative return moves. In another example, the FLL stock shows a convergent bipolar behavior during mania market mood. This is evident from comparing its loci in panel (a) and (d) where a segmented return pattern herds with highly integrated stocks when market changes to mania mood. In the third example, the stock PNC is integrated with market stocks during normal days and this high integration collapses during the depression, chaos and mania market moods as an indication of a complete divergent bipolar behavior. In the last example, we see the stock BAP having convergent bipolar behavior during a chaos 
market mood. This can be concluded from comparing its movement with aggregate that shows change in a segmented return pattern to herding with highly integrated stocks during chaos market mood.

Despite the importance of MDS when dealing with the spatial structure of stock return in a two-dimensional space, it has three major problems: First, the two-dimensional map in MDS is not an accurate abstraction of the (dis)similarity matrix. As noted in section 3.2, it is an estimation approach that basically minimizing the error between D and $\mathrm{D}^{\prime}$ distance matrices given by Eq. (4). On the other hand, the visual reports of the MDS (also in the AHC) is highly sensitive to the highly outlier stocks. In fact, if you had a highly segmented stock in your analysis, you will need to visualize the MDS panel in a very big screen or rescale it that in either case, it loses the intended visual properties. Finally, it does not show the stock-cluster of stocks relations. In the next step, we solve the third problem by applying the AHC algorithm using the average linkage metric $d\left((\delta)_{i, j}\right)$. The other two problems are addressed in the baseline model CEN (Sec. 4.2).

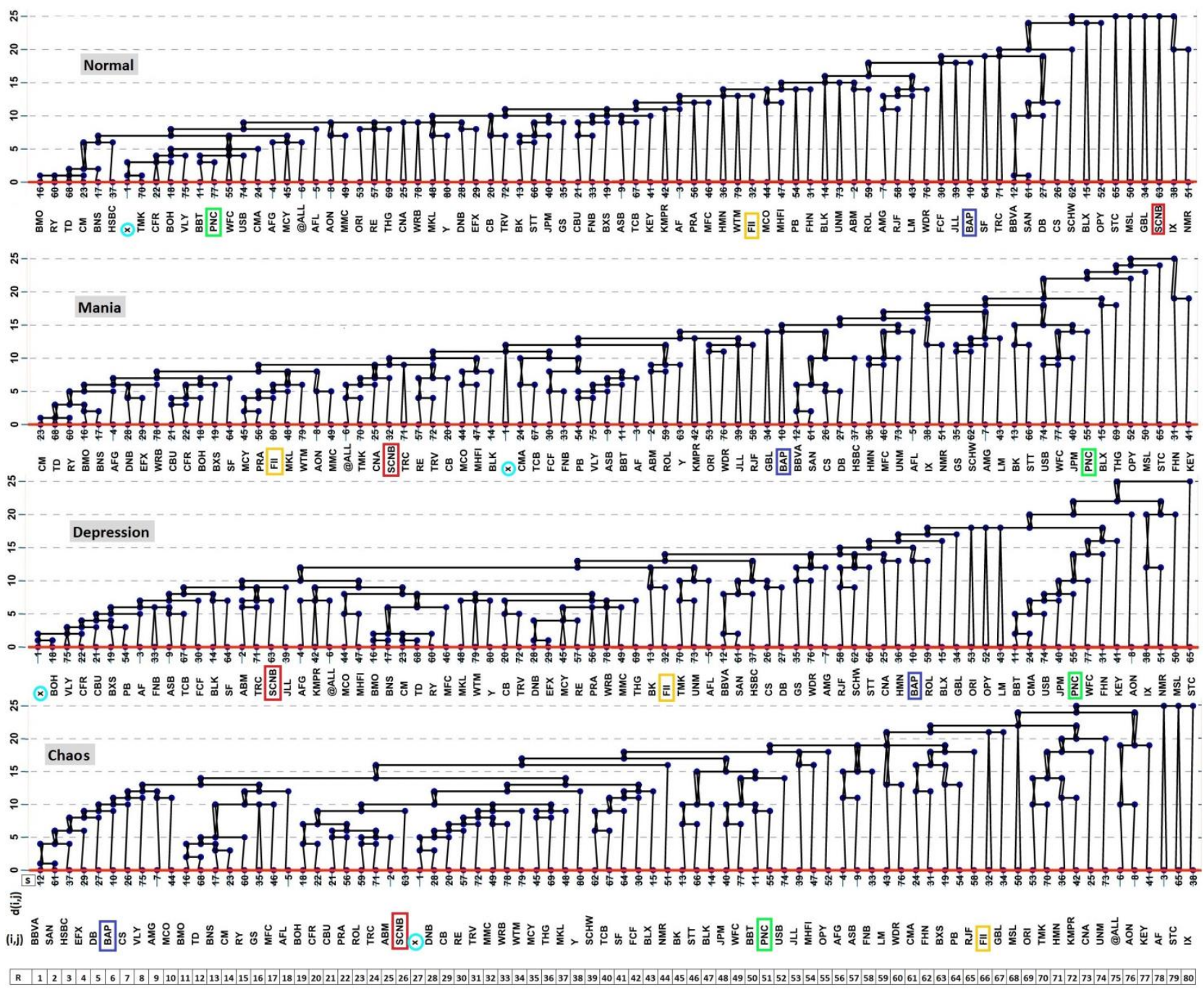

Fig 4. Hierarchical networks during different market moods. This figure displays stock dendrograms where each stock has an ordinal rank of (dis)similarity with the market. The left and right side of the dendrograms has a short and long vertical line representing the maximum and minimum similarities among ranked stocks. This scaled scheme addresses the (dis)similarity of both stock-stock and stock-cluster of stocks return patterns.

Considering the same example stocks from MDS panels (Fig. 3), we can trace their bipolar behavior from the dendrograms in Fig. 4. We see the PNC (green colored) as a highly integrated stock during normal market mood at the left side changes its synchronized return move to a segmented pattern during all extreme market moods referring to a divergent bipolar disorder. In the second example, we have the SCNB (red on the map) a highly segmented stock at the end tail of the normal panel with high 
dissimilarity rank. In the other panels (mania, depression and chaos), its dissimilarity closes to zero as noted by a convergent bipolar disorder. In another example, BAP is a dissimilar stock at the end tail of the normal panel that remains (relatively) stable during mania and depression market moods but shifts to a highly integrated pattern with other stocks during the chaos market mood (a convergent bipolar behavior).

\subsection{Results from CEN model}

In this section, we study the CEN structure and dynamics of stock return during different market moods. According to the discussed methodology, we use featured data sets identified in Sec. 3.1 to characterize the set of networks $G_{80,3160}^{\theta}$ with $n=$ 80 nodes and $\mathrm{K}=3160$ edges in $\theta$ market moods. In this network structure, the nodes are stocks and the edge lengths denote the strength of pairwise (dis)similarity in the time-varying return pattern. In that way, the set of $80 \times 80$ symmetric matrixes $\mathrm{L}^{\theta}=$ $\left\{L^{\tilde{n}}, L^{m}, L^{c}, L^{d}\right\}$ describes networks with elements $L^{\theta}{ }_{i, j}$ equal to the weights of existing edges drive from $m^{\theta}$ dimensional space. These quantities provide a general characterization of the suggested CEN model. In the next step, we calculate the alpha measure and network dispersion as two measures of understanding the structure of suggested multi-state network. We use $\mathrm{L}^{\theta}$ in Eq. (8) and Eq. (9) to calculate the $\propto^{\theta}$ and $\overline{\mathrm{L}}^{\theta}$ respectively. Table 1 shows the descriptive statistics of these measures for each state and four example stocks.

Table 1

Descriptive statistics of the alpha measure and network dispersion coefficient

\begin{tabular}{cccccccccccccc}
\hline $\mathrm{N}=80$ & $\begin{array}{c}\text { Mean } \\
\bar{\alpha}^{\theta}=\bar{L}^{\theta}\end{array}$ & Median & St.d & Kurtosis & Skew & Range & Min & Max & Sum & BAP & FLL & PNC & SCNB \\
\hline$\propto_{i}^{\tilde{n}}$ & 3.85 & 3.61 & 0.88 & 0.14 & 0.84 & 3.93 & 1.97 & 5.9 & 308 & 4.7 & 3.9 & 3.0 & 5.8 \\
$\propto_{i}^{m}$ & 23.79 & 22.8 & 4.96 & 1.54 & 1.1 & 25.48 & 16.25 & 41.74 & 1903 & 25.9 & 19.2 & 30.9 & 25.0 \\
$\propto_{i}^{d}$ & 21.18 & 20.24 & 4.69 & 1.43 & 1.04 & 24.03 & 10.86 & 34.89 & 1695 & 23.7 & 19.5 & 27.2 & 18.9 \\
$\propto_{i}^{C}$ & 28.85 & 28.38 & 5.86 & 0.25 & 0.47 & 31.53 & 14.75 & 46.28 & 2308 & 24.0 & 35.6 & 29.7 & 27.7 \\
\hline
\end{tabular}

Comparing the alpha measures among states reports a considerable increase in the mean, median and Std. measures of centrality when market mood changes from normal to extreme market moods. Notably, the average of alpha (equal to the clustering coefficient) for extreme market moods $(23.79,21.18$, and 28.85$)$ is almost seven times greater than the normal market mood average. However, these statistics are only slightly different among abnormal states. The highest dispersion is in the chaos market mood where mean, median and Std. increase from 3.85, 3.61, 0.88 to 28.85, 28.38 and 5.86 respectively. The same results can also be understood from comparing the sum column among the states. We can see the same scale effect on the closeness centrality of the example stocks. In the next section, we would analyze such a dynamics with more details. To better highlight the asymmetric behavior of alpha measure during normal days and the days of market stress, we look at its probability distribution in Fig. 5. For comparability among different market moods, we normalized the alpha measure between zero and one.

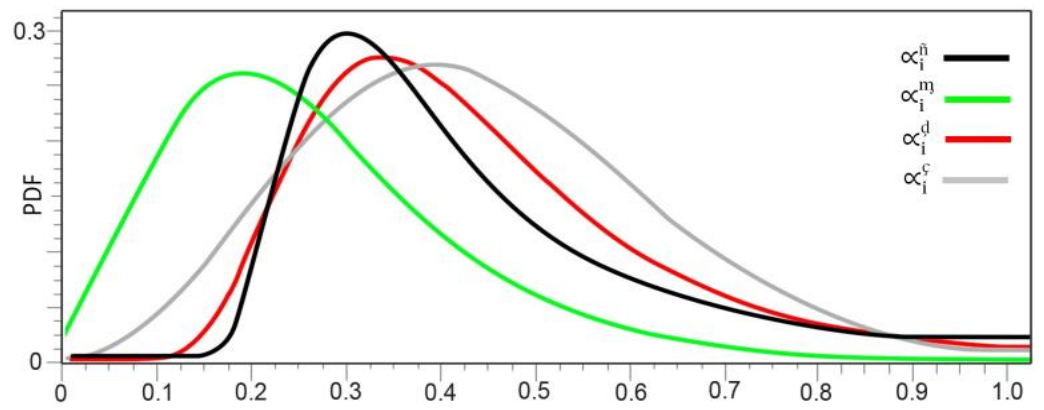

Fig 5 . Probability density of normalized $\propto$ measure In this figure, we present the probability density function of $\propto$ measure for each individual stock during $\theta$ market moods. The left side of the chart accounts for the stocks with synchronous aggregate behavior and the right side is about the highly segmented stocks. 
As shown in the Fig. 5, we have a relatively symmetric distribution for chaos market mood noted by a grey line. The normally distributed feature of alpha measure implies that the probability of extremely segmented return patterns is very low compared to the long tail distributions. For the three other market moods, we observe a positively skewed distribution (also given in Table 1) which identifies the community structure (in the hump) and the high possibility of observing segmented stocks abnormally distant from the center of the network (tail part). With all the importance of the state dependent alpha measure, we cannot use it for quantifying the global and self-organized dynamics of alpha measure. This level of knowledge requires other calculations that we do in the next section.

\subsubsection{Return dynamics in the applied CEN model}

In this section, we calculate the network dynamics of stock return as the final output and the main purpose of the suggested CEN model. For capturing the global dynamics we basically divide the average of edge length (same with the average of alpha measure) in an abnormal market mood to its normal market component. We use $\overline{\mathrm{L}}^{\theta}$ from the second column of Table 1 and calculate the global dynamics set $\stackrel{\tilde{n} \rightarrow a}{g}=\{6.18,5.5,7.5\}$ with elements corresponding to the $m_{3}$ d, ç market moods respectively. As like observed in Sec. 4.2, we have a considerable dispersion during abnormal moods compared to normal mood. However, we do not see a considerable difference among abnormal states' global dynamics. In the next step, we calculate the self-organized dynamics which accounts for the magnitude and sign of the SBB. In the next stage, we exclude this global dynamics from the alpha measures of the abnormal states using Eq. (8-2).

Table 2 reports the descriptive statistics of $\propto_{i}^{a \mid \tilde{n}}$ for all three abnormal market moods and four selected example stocks. As we see in Table 2, the average and sum of transformed alpha measure is the same in all market moods. On the other hand, the Kurtosis and skewness of transformed alpha measure in chaos market mood is considerably low in comparison with the other abnormal states. Comparing the Min and Max columns with the Mean column reveals that the absolute difference between max and mean is much greater than the same between min and mean. This result shows that the possibility of observing highly segmented return pattern is much higher than the highly integrated stocks. Comparing centrality statistics, we do not see a significant difference among the transformed alpha measure of all abnormal market moods. In the next step, we apply Eq. (11) and calculate SBB by simply taking the difference between $\propto_{i}^{a}$ and $\alpha_{i}^{a \mid \tilde{n}}$. Then, we use Eq. (11-3) and calculate the MBB of each state. Finally, the sum of MBB from each state gives us the total MBB as the final result. We report these results in Table (2).

Table 2

Descriptive statistics of the transformed alpha measure and SBB

\begin{tabular}{|c|c|c|c|c|c|c|c|c|c|c|c|c|c|c|c|}
\hline $\mathrm{N}=80$ & $\bar{\alpha}^{\theta}=\overline{\mathrm{L}}^{\theta}$ & Median & Std & Kurtosis & Skew & Range & Min & Max & Sum & $\Omega^{a}$ & $\Omega$ & BAP & FLL & PNC & SCNB \\
\hline$\alpha_{i}^{m \mid \tilde{n}}$ & 3.85 & 3.70 & 0.80 & 1.54 & 1.10 & 4.13 & 2.63 & 6.76 & 308 & & & 4.2 & 3.1 & 5.0 & 4.0 \\
\hline$\propto_{i}^{c \mid \tilde{n}}$ & 3.85 & 3.68 & 0.85 & 1.43 & 1.04 & 4.37 & 1.98 & 6.35 & 308 & & & 4.3 & 3.5 & 4.9 & 3.4 \\
\hline$\propto_{i}^{\mathrm{d}} \mid \tilde{\mathrm{n}}$ & 3.85 & 3.79 & 0.78 & 0.25 & 0.47 & 4.21 & 1.97 & 6.18 & 308 & & 162 & 3.2 & 4.7 & 3.9 & 3.7 \\
\hline$\Omega_{\mathrm{i}}^{\mathrm{m}}$ & 0 & -0.05 & 0.9 & 1.8 & 0.7 & 5.0 & -1.8 & 3.2 & 0 & 48.6 & & -0.5 & -0.77 & 2.00 & -1.79 \\
\hline$\Omega_{\mathrm{i}}^{\mathrm{d}}$ & 0 & -0.05 & 0.9 & 1.4 & 0.5 & 5.2 & -2.4 & 2.8 & 0 & 50.8 & & -0.4 & -0.33 & 1.93 & -2.39 \\
\hline$\Omega_{i}^{C}$ & 0 & 0 & 1.0 & 0.1 & 0.2 & 4.9 & -2.1 & 2.8 & 0 & 62.7 & & -1.5 & 0.87 & 0.96 & -2.14 \\
\hline
\end{tabular}

Analyzing results in the aggregate level (macro results) shows that there is no significant difference in MBB between mania and depression abnormal market moods $(48.6,50.8)$. However, MBB in chaos market mood is notably higher $(62.7)$ than other abnormal states. A higher MBB for a state shows that most of the stocks in that state have changed their behavior by market transition to that abnormal state and vice versa. In the same way, the total MBB denoted by $\Omega=162$ shows the sum of absolute SBB for all stocks and all abnormal states. This measure must be compared with other similar market and the results of a parallel study. 
Next, we analyze the quantitative results for the selected example stocks (micro results) which can be followed from the visual results of the MDS and AHC models. From Table 2, we see BAP stock has a high negative (-1.5) SBB that belongs to its convergent bipolar behavior. This number describes BAP as a segmented stock during normal days that clearly changes its behavior towards integration with the market during market transition to chaos mood. Result for FLL shows high convergent and divergent SBB during mania and chaos market moods respectively. Analyzing the SBB between PNC and SCNB stocks shows that both of them have a highly erratic dynamic during all abnormal market moods. However, the positive sign in PNC and the negative sign in SCNB describe them with a divergent and convergent bipolar behavior respectively.

\section{Summary and conclusion}

The picture of capital markets as groups of interacting traders, continually adapting to new information and reflecting them in prices seems like a much adopted picture of capital markets theory (Small, 2005). However, In contrast to such a simple microscopic structure, the macroscopic behavior of stock prices appears to be a surprisingly complex and nonlinear phenomenon. In the decision science and human dynamics literature, this remarkable macroscopic behavior and the existence of typical patternlike structures has been highly tied with (deterministic) traders psychology and a strong desire to make profits coupled with fear of losing. With such a highly nonlinear autocatalytic structure of traders beliefs, modeling return dynamics is extremely difficult with respect to both temporal and ensemble autocatalytic properties. These levels of complexity reinforce the idea of a stock market as a complex system possessing a structure spanning several scales.

In this context, we presented a spatiotemporal CEN model with the edges weighted by log return (dis)similarity to study the nonlinear process of interactions in traders' belief and its aspiration in the aggregate dynamics of stock return. This approach addresses the influential role of complex system analysis in understanding the temporal and autocatalytic behavior of stock markets. To reduce the complexity and uncover the main characteristics of stock return we adopt the spectral properties of the distance ((dis)similarity) matrix. Uncovering these (dis)similarities through the network dynamics of stock returns generates meaningful insights about the stocks' and market's mass psychology. In particular, we demonstrate that changes in the state of the market are an important determinant of a self-organized change in stocks' collective (network) return behavior.

Our approach scales market time into normal and extreme episodes (depression, mania and chaos) and constructs a spatial representation of (dis)similar stocks within a multi-state CEN framework. Tracing each stock's network transformation during these episodes demonstrates that returns have both global and self-organized dynamics. We model and interpret the selforganized dynamics for each stock and the entire market as evidence of SBB and MBB. We establish that SBB occurs in two opposite directions: convergent SBB and divergent SBB. In a high convergent SBB, a stock with abnormal return pattern changes its segmented trend toward a highly synchronized return move with most integrated stocks. On the other hand, in a high divergent SBB, a stock with synchronized return pattern breaks its linkage with aggregate when market moves to an abnormal mood. Mathematically, convergent and divergent SBB are expressed by negative and positive values where SBB close to zero accounts for a stable stock which remains stable in its network position during transition to the out-of-equilibrium market moods.

The first empirical evidence of the proposed model indicates that network dispersion increases significantly during all periods of major absolute price movements (positive, negative and chaos market mood). These results can be identified from the outputs of the alpha measure and global dynamics coefficient. These results are also consistent with the predictions of rational asset pricing where dispersion in stocks' collective returns is significantly higher than average during days characterized by large swings in average price. However, the rationality hypothesis does not report the asymmetric behavior of individual stocks that emerges during phase transition in the market state. In the CEN model, this problem is assessed by devising a mathematical approach that differentiates global return dynamics (same for all stocks) from the self-organized dynamics of each individual stock. This level of knowledge reveals a variety of stylized facts regarding stocks' and market's heterogeneous response to the extreme conditions in the market.

We believe suggested CEN model provides an improved understanding of financial markets' complex network behavior under changing market condition. This may, in turn, improve the knowledge of underlying economic and financial factors that 
characterize and influence market behavior. In the finance literature, the particular application domain can include the effective portfolio management, contagion and volatility analysis. Our future work in this direction will investigate different network measures with their application in understanding the network structure and dynamics of CEN model.

\section{Appendix (A): Extension of the model to the edge length}

$$
\begin{aligned}
& 2 \sum_{\mathrm{i}} \sum_{\mathrm{j}} l_{\mathrm{i}, \mathrm{j}}^{\mathrm{a}} \\
& (10),(9) \Rightarrow \mathrm{f}^{\tilde{n} \rightarrow \mathrm{a}}=\frac{\frac{2 \sum_{\mathrm{i}} \sum_{\mathrm{j}} l_{\mathrm{i}, \mathrm{j}}^{\mathrm{a}}\left(\mathrm{n}^{\mathrm{a}}-1\right)}{2 \sum_{\mathrm{i}} \sum_{\mathrm{j}} l_{\mathrm{i}, \mathrm{j}}^{\tilde{\mathrm{n}}}}}{\frac{\mathrm{n}^{\tilde{\mathrm{n}}}\left(\mathrm{n}^{\tilde{n}}-1\right)}{\mathrm{n}^{\tilde{n}}\left(\mathrm{n}^{\tilde{n}}-1\right) \sum_{\mathrm{i}} \sum_{\mathrm{j}} l_{\mathrm{i}, \mathrm{j}}^{\mathrm{a}}}}=\quad(10-1) \\
& (8-2),(10-1),(8) \Rightarrow \propto_{i}^{\mathrm{a} \mid \tilde{n}}=\left(\frac{\mathrm{n}^{\tilde{n}}\left(\mathrm{n}^{\tilde{n}}-1\right) \sum_{\mathrm{i}} \sum_{\mathrm{j}} l_{\mathrm{i}, \mathrm{j}}^{\mathrm{a}}}{\mathrm{n}^{\mathrm{a}}\left(\mathrm{n}^{\mathrm{a}}-1\right) \sum_{\mathrm{i}} \sum_{\mathrm{j}} l_{\mathrm{i}, \mathrm{j}}^{\tilde{n}}}\right)^{-1}\left(\frac{\sum_{\mathrm{j}} l_{\mathrm{i}, \mathrm{j}}^{\mathrm{a}}}{\mathrm{n}^{\mathrm{a}}-1}\right)=\frac{\mathrm{n}^{\mathrm{a}}\left(\sum_{\mathrm{j}} l_{\mathrm{i}, \mathrm{j}}^{\mathrm{a}}\right)\left(\sum_{\mathrm{i}} \sum_{\mathrm{j}} l_{\mathrm{i}, \mathrm{j}}^{\tilde{n}}\right)}{\mathrm{n}^{\tilde{n}}\left(\mathrm{n}^{\tilde{n}}-1\right)\left(\sum_{\mathrm{i}} \sum_{\mathrm{j}} l_{\mathrm{i}, \mathrm{j}}^{\mathrm{a}}\right)} \quad(8-3) \\
& \text { (11), (8-3), (8) } \Rightarrow \Omega_{\mathrm{i}}^{\mathrm{a}}=\frac{\mathrm{n}^{\mathrm{a}}\left(\sum_{\mathrm{j}} l_{\mathrm{i}, \mathrm{j}}^{\mathrm{a}}\right)\left(\sum_{\mathrm{i}} \sum_{\mathrm{j}} l_{\mathrm{i}, \mathrm{j}}^{\tilde{\tilde{n}}}\right)}{\mathrm{n}^{\tilde{n}}\left(\mathrm{n}^{\tilde{n}}-1\right)\left(\sum_{\mathrm{i}} \sum_{\mathrm{j}} l_{\mathrm{i}, \mathrm{j}}^{\mathrm{a}}\right)}-\frac{\sum_{\mathrm{j}} l_{\mathrm{i}, \mathrm{j}}^{\tilde{n}}}{\mathrm{n}^{\tilde{n}}-1}=\frac{\mathrm{n}^{\mathrm{a}}\left(\sum_{\mathrm{j}} l_{\mathrm{i}, \mathrm{j}}^{\mathrm{a}}\right)\left(\sum_{\mathrm{i}} \sum_{\mathrm{j}} l_{\mathrm{i}, \mathrm{j}}^{\tilde{n}}\right)-\mathrm{n}^{\tilde{n}}\left(\sum_{\mathrm{j}} l_{\mathrm{i}, \mathrm{j}}^{\tilde{n}}\right)\left(\sum_{\mathrm{i}} \sum_{\mathrm{j}} l_{\mathrm{i}, \mathrm{j}}^{\mathrm{a}}\right)}{\mathrm{n}^{\tilde{n}}\left(\mathrm{n}^{\tilde{n}}-1\right)\left(\sum_{\mathrm{i}} \sum_{\mathrm{j}} l_{\mathrm{i}, \mathrm{j}}^{\mathrm{a}}\right)} \quad(11-1)
\end{aligned}
$$

\section{Appendix (B): Extension of the model to the data elements}

$$
\begin{aligned}
& (10-1),(7) \Rightarrow \mathrm{f}^{\tilde{\mathrm{n}} \rightarrow \mathrm{a}}=\frac{\mathrm{n}^{\tilde{n}}\left(\mathrm{n}^{\tilde{n}}-1\right)\left(\sum_{\mathrm{i}} \sum_{\mathrm{j}}\left(\frac{\sum_{\mathrm{t}}\left(\mathrm{r}_{\mathrm{t}, \mathrm{i}}^{\mathrm{a}}-\mathrm{r}_{\mathrm{t}, \mathrm{j}}^{\mathrm{a}}\right)^{2}}{\mathrm{~m}^{\mathrm{a}}}\right)^{\frac{1}{2}}\right)}{\mathrm{n}^{\mathrm{a}}\left(\mathrm{n}^{\mathrm{a}}-1\right)\left(\sum_{\mathrm{i}} \sum_{\mathrm{j}}\left(\frac{\sum_{\mathrm{t}}\left(\mathrm{r}_{\mathrm{t}, \mathrm{i}}^{\tilde{n}}-\mathrm{r}_{\mathrm{t}, \mathrm{j}}^{\tilde{n}}\right)^{2}}{\mathrm{~m}^{\tilde{n}}}\right)^{\frac{1}{2}}\right)}=\frac{\mathrm{n}^{\tilde{\mathrm{n}}}\left(\mathrm{n}^{\tilde{\mathrm{n}}}-1\right)\left(\sum_{\mathrm{i}} \sum_{\mathrm{j}}\left(\mathrm{m}^{\tilde{\mathrm{n}}} \sum_{\mathrm{t}}\left(\mathrm{r}_{\mathrm{t}, \mathrm{i}}^{\mathrm{a}}-\mathrm{r}_{\mathrm{t}, \mathrm{j}}^{\mathrm{a}}\right)^{2}\right)^{\frac{1}{2}}\right)}{\mathrm{n}^{\mathrm{a}}\left(\mathrm{n}^{\mathrm{a}}-1\right)\left(\sum_{\mathrm{i}} \sum_{\mathrm{j}}\left(\mathrm{m}^{\mathrm{a}} \sum_{\mathrm{t}}\left(\mathrm{r}_{\mathrm{t}, \mathrm{i}}^{\tilde{n}}-\mathrm{r}_{\mathrm{t}, \mathrm{j}}^{\tilde{n}}\right)^{2}\right)^{\frac{1}{2}}\right)} \\
& (8-3),(7) \Rightarrow \alpha_{i}^{\mathrm{a} \mid \tilde{n}}=\left(\frac{\mathrm{n}^{\mathrm{a}}\left(\sum_{\mathrm{j}}\left(\frac{\sum_{\mathrm{t}}\left(\mathrm{r}_{\mathrm{t}, \mathrm{i}}^{\mathrm{a}}-\mathrm{r}_{\mathrm{t}, \mathrm{j}}^{\mathrm{a}}\right)^{2}}{\mathrm{~m}^{\mathrm{a}}}\right)^{\frac{1}{2}}\right)\left(\sum_{\mathrm{i}} \sum_{\mathrm{j}}\left(\frac{\sum_{\mathrm{t}}\left(\mathrm{r}_{\mathrm{t}, \mathrm{i}}^{\tilde{n}}-\mathrm{r}_{\mathrm{t}, \mathrm{j}}^{\tilde{n}}\right)^{2}}{\mathrm{~m}^{\tilde{n}}}\right)^{\frac{1}{2}}\right)}{\mathrm{n}^{\tilde{n}}\left(\mathrm{n}^{\tilde{n}}-1\right)\left(\sum_{\mathrm{i}} \sum_{\mathrm{j}}\left(\frac{\sum_{\mathrm{t}}\left(\mathrm{r}_{\mathrm{t}, \mathrm{i}}^{\mathrm{a}}-\mathrm{r}_{\mathrm{t}, \mathrm{j}}^{\mathrm{a}}\right)^{2}}{\mathrm{~m}^{\mathrm{a}}}\right)^{\frac{1}{2}}\right)}\right) \\
& =\frac{\mathrm{n}^{\mathrm{a}}\left(\sum_{\mathrm{i}} \sum_{\mathrm{j}}\left(\sum_{\mathrm{t}}\left(\mathrm{r}_{\mathrm{t}, \mathrm{i}}^{\tilde{\mathrm{n}}}-\mathrm{r}_{\mathrm{t}, \mathrm{j}}^{\tilde{\mathrm{n}}}\right)^{2}\right)^{\frac{1}{2}}\right)\left(\sum_{\mathrm{j}}\left(\sum_{\mathrm{t}}\left(\mathrm{r}_{\mathrm{t}, \mathrm{i}}^{\mathrm{a}}-\mathrm{r}_{\mathrm{t}, \mathrm{j}}^{\mathrm{a}}\right)^{2}\right)^{\frac{1}{2}}\right)}{\mathrm{n}^{\tilde{n}}\left(\mathrm{n}^{\tilde{\mathrm{n}}}-1\right)\left(\sum_{\mathrm{i}} \sum_{\mathrm{j}}\left(\mathrm{m}^{\tilde{\mathrm{n}}} \sum_{\mathrm{t}}\left(\mathrm{r}_{\mathrm{t}, \mathrm{i}}^{\mathrm{a}}-\mathrm{r}_{\mathrm{t}, \mathrm{j}}^{\mathrm{a}}\right)^{2}\right)^{\frac{1}{2}}\right)} \quad(8-4) \\
& (11-1),(8-4),(7) \Rightarrow \Omega_{\mathrm{i}}^{\mathrm{a}}=\frac{\mathrm{n}^{\mathrm{a}}\left(\sum_{\mathrm{i}} \sum_{\mathrm{j}}\left(\sum_{\mathrm{t}}\left(\mathrm{r}_{\mathrm{t}, \mathrm{i}}^{\tilde{n}}-\mathrm{r}_{\mathrm{t}, \mathrm{j}}^{\tilde{n}}\right)^{2}\right)^{\frac{1}{2}}\right)\left(\sum_{\mathrm{j}}\left(\sum_{\mathrm{t}}\left(\mathrm{r}_{\mathrm{t}, \mathrm{i}}^{\mathrm{a}}-\mathrm{r}_{\mathrm{t}, \mathrm{j}}^{\mathrm{a}}\right)^{2}\right)^{\frac{1}{2}}\right)}{\mathrm{n}^{\tilde{n}}\left(\mathrm{n}^{\tilde{\mathrm{n}}}-1\right)\left(\sum_{\mathrm{i}} \sum_{\mathrm{j}}\left(\mathrm{m}^{\tilde{\mathrm{n}}} \sum_{\mathrm{t}}\left(\mathrm{r}_{\mathrm{t}, \mathrm{i}}^{\mathrm{a}}-\mathrm{r}_{\mathrm{t}, \mathrm{j}}^{\mathrm{a}}\right)^{2}\right)^{\frac{1}{2}}\right)}-\frac{\sum_{\mathrm{j}}\left(\frac{\sum_{\mathrm{t}}\left(\mathrm{r}_{\mathrm{t}, \mathrm{i}}^{\tilde{n}}-\mathrm{r}_{\mathrm{t}, \mathrm{j}}^{\tilde{n}}\right)^{2}}{\mathrm{~m}^{\tilde{n}}}\right)^{\frac{1}{2}}}{\mathrm{n}^{\tilde{n}}-1} \\
& =\frac{\left(\mathrm{n}^{\mathrm{a}}\left(\sum_{\mathrm{i}} \sum_{\mathrm{j}}\left(\sum_{\mathrm{t}}\left(\mathrm{r}_{\mathrm{t}, \mathrm{i}}^{\tilde{\mathrm{n}}}-\mathrm{r}_{\mathrm{t}, \mathrm{j}}^{\tilde{\mathrm{n}}}\right)^{2}\right)^{\frac{1}{2}}\right)\left(\sum_{\mathrm{j}}\left(\sum_{\mathrm{t}}\left(\mathrm{r}_{\mathrm{t}, \mathrm{i}}^{\mathrm{a}}-\mathrm{r}_{\mathrm{t}, \mathrm{j}}^{\mathrm{a}}\right)^{2}\right)^{\frac{1}{2}}\right)\right)-\left(\mathrm{n}^{\tilde{\mathrm{n}}}\left(\sum_{\mathrm{j}}\left(\sum_{\mathrm{t}}\left(\mathrm{r}_{\mathrm{t}, \mathrm{i}}^{\tilde{n}}-\mathrm{r}_{\mathrm{t}, \mathrm{j}}^{\tilde{n}}\right)^{2}\right)^{\frac{1}{2}}\right)\left(\sum_{\mathrm{i}} \sum_{\mathrm{j}}\left(\sum_{\mathrm{t}}\left(\mathrm{r}_{\mathrm{t}, \mathrm{i}}^{\mathrm{a}}-\mathrm{r}_{\mathrm{t}, \mathrm{j}}^{\mathrm{a}}\right)^{2}\right)^{\frac{1}{2}}\right)\right)}{n^{\tilde{n}}\left(\mathrm{n}^{\tilde{n}}-1\right)\left(\sum_{\mathrm{i}} \sum_{\mathrm{j}}\left(\mathrm{m}^{\tilde{n}} \sum_{\mathrm{t}}\left(\mathrm{r}_{\mathrm{t}, \mathrm{i}}^{\mathrm{a}}-\mathrm{r}_{\mathrm{t}, \mathrm{j}}^{\mathrm{a}}\right)^{2}\right)^{\frac{1}{2}}\right)}
\end{aligned}
$$




\section{References}

Baele, Lieven, Ferrando, Annalisa, Hördahl, Peter, Krylova, Elizaveta, \& Monnet, Cyril. (2004). Measuring European financial integration. Oxford Review of Economic Policy, 20(4), 509-530.

Baker, Malcolm, \& Wurgler, Jeffrey. (2006). Investor sentiment and the cross-section of stock returns. The Journal of Finance, 61(4), 1645-1680. Barberis, Nicholas, Shleifer, Andrei, \& Vishny, Robert. (1998). A model of investor sentiment. Journal of financial economics, 49(3), 307-343.

BAYDiLLi, Yusuf YargI, BAYIR, Şafak, \& TÜRKER, illker. (2017). A HIERARCHICAL VIEW OF A NATIONAL STOCK MARKET AS A COMPLEX NETWORK. Economic Computation \& Economic Cybernetics Studies \& Research, 51(1).

Belmaker, RH. (2004). Bipolar disorder. New England Journal of Medicine, 351(5), 476-486.

Boginski, Vladimir, Butenko, Sergiy, \& Pardalos, Panos M. (2006). Mining market data: a network approach. Computers \& Operations Research, 33(11), 3171-3184.

Byun, Suk Joon, Lim, Sonya S, \& Yun, Sang Hyun. (2016). Continuing overreaction and stock return predictability. Journal of Financial and Quantitative Analysis, 51(6), 2015-2046.

Campbell, John Y, \& Thompson, Samuel B. (2008). Predicting excess stock returns out of sample: Can anything beat the historical average? Review of Financial Studies, 21(4), 1509-1531.

Carroll, Douglas, \& Wish, Myron. (1975). Multidimensional Scaling: Models, Methods, and Relationships to Delphi. The Delphi Method book: see Linstone and Turoff.

CARROLL, J DOUGLAS, \& WISH, MYRON. (1975). VI. C. Multidimensional Scaling: Models, Methods, and Relations to Delphi. The Delphi method: techniques and applications, 402.

Cenesizoglu, Tolga, \& Timmermann, Allan G. (2008). Is the distribution of stock returns predictable? Available at SSRN 1107185.

Cheung, James HB. (2010). Does Mr. Market Suffer from Bipolar Disorder? Journal of Behavioral Finance, 11(4), $224-238$.

Engelberg, Joseph, \& Parsons, Christopher A. (2016). Worrying about the stock market: Evidence from hospital admissions. The Journal of Finance.

Esmalifalak, Hamidreza, Ajirlou, Ali Irannezhad, Behrouz, Sahar Pordeli, \& Esmalifalak, Maryam. (2015). (Dis) integration levels across global stock markets: A multidimensional scaling and cluster analysis. Expert Systems with Applications, 42(22), 8393-8402.

Fama, Eugene F. (1970). Efficient capital markets: A review of theory and empirical work. The journal of Finance, 25(2), $383-417$.

Fama, Eugene F. (1995). Random walks in stock market prices. Financial analysts journal, 51(1), 75-80.

Graham, Benjamin, \& Zweig, Jason. (2003). The intelligent investor: HarperBusiness Essentials.

Greenwald, Bruce CN, Kahn, Judd, Sonkin, Paul D, \& Van Biema, Michael. (2004). Value investing: from Graham to Buffett and beyond: John Wiley \& Sons.

Guo, Hui, \& Savickas, Robert. (2006). Idiosyncratic volatility, stock market volatility, and expected stock returns. Journal of Business \& Economic Statistics, 24(1), 43-56.

Hilton, Denis J. (2001). The psychology of financial decision-making: Applications to trading, dealing, and investment analysis. The Journal of Psychology and Financial Markets, 2(1), 37-53.

Hirshleifer, David, \& Shumway, Tyler. (2003). Good day sunshine: Stock returns and the weather. The Journal of Finance, 58(3), $1009-1032$.

Huang, Wei-Qiang, Yao, Shuang, Zhuang, Xin-Tian, \& Yuan, Ying. (2017). Dynamic asset trees in the US stock market: Structure variation and market phenomena. Chaos, Solitons \& Fractals, 94, 44-53.

Kantar, E, Deviren, B, \& Keskin, M. (2011). Investigation of major international and Turkish companies via hierarchical methods and bootstrap approach. The European Physical Journal B-Condensed Matter and Complex Systems, 84(2), 339-350.

Keynes, John Maynard. (1937). The general theory of employment. The quarterly journal of economics, $209-223$.

Keynes, John Maynard. (2006). General theory of employment, interest and money: Atlantic Publishers \& Dist.

Kristoufek, Ladislav, \& Vosvrda, Miloslav. (2013). Measuring capital market efficiency: Global and local correlations structure. Physica A: Statistical Mechanics and its Applications, 392(1), 184-193.

Lawrence, Edward R, McCabe, George, \& Prakash, Arun J. (2007). Answering financial anomalies: Sentiment-based stock pricing. The journal of behavioral finance, 8(3), 161-171.

Lillo, Fabrizio, Farmer, J Doyne, \& Mantegna, Rosario N. (2003). Econophysics: Master curve for price-impact function. Nature, 421(6919), 129130.

Lo, Andrew W. (2004). The adaptive markets hypothesis: Market efficiency from an evolutionary perspective. Journal of Portfolio Management, Forthcoming.

Lunde, Asger, \& Timmermann, Allan. (2012). Duration dependence in stock prices. Journal of Business \& Economic Statistics.

Mantegna, Rosario N. (1999). Hierarchical structure in financial markets. The European Physical Journal B-Condensed Matter and Complex Systems, 11(1), 193-197.

Mantegna, Rosario N, \& Stanley, H Eugene. (2000). An introduction to econophysics: correlation and complexity in finance: Cambridge University Press, Cambridge.

McCauley, Joseph L. (2006). DYNAMICS OF MARKETS: ECONOPHYSICS AND FINANCE.

Muñoz Torrecillas, María José, Yalamova, Rossitsa, \& McKelvey, Bill. (2016). Identifying the Transition from Efficient-Market to Herding Behavior: Using a Method from Econophysics. Journal of Behavioral Finance, 17(2), 157-182.

Nofsinger, John. (2016). The psychology of investing: Routledge.

Olson, Kenneth R. (2006). A literature review of social mood. The Journal of Behavioral Finance, 7(4), $193-203$.

Otuteye, Eben, \& Siddiquee, Mohammad. (2015). Overcoming cognitive biases: A heuristic for making value investing decisions. Journal of Behavioral Finance, 16(2), 140-149. 
Pan, Raj Kumar, \& Sinha, Sitabhra. (2007). Collective behavior of stock price movements in an emerging market. Physical Review E, 76(4), 046116.

Siganos, Antonios, Vagenas-Nanos, Evangelos, \& Verwijmeren, Patrick. (2017). Divergence of sentiment and stock market trading. Journal of Banking \& Finance, 78, 130-141.

Small, Michael. (2005). Applied nonlinear time series analysis: applications in physics, physiology and finance (Vol. 52): World Scientific.

Sornette, Didier. (2003). Why stock market crash.

Ulusoy, Tolga, Keskin, Mustafa, Shirvani, Ayoub, Deviren, Bayram, Kantar, Ersin, \& Çağrı Dönmez, Cem. (2012). Complexity of major UK companies between 2006 and 2010: Hierarchical structure method approach. Physica A: Statistical Mechanics and its Applications, $391(21), 5121-5131$.

Urquhart, Andrew, \& Hudson, Robert. (2013). Efficient or adaptive markets? Evidence from major stock markets using very long run historic data. International Review of Financial Analysis, 28, 130-142.

Urquhart, Andrew, \& McGroarty, Frank. (2014). Calendar effects, market conditions and the Adaptive Market Hypothesis: Evidence from longrun US data. International Review of Financial Analysis, 35, 154-166.

Vieito, João Paulo, da Rocha, Armando Freitas, \& Rocha, Fabio Theoto. (2015). Brain activity of the investor's stock market financial decision. Journal of Behavioral Finance, 16(3), 220-230.

Yang, Yue, \& Yang, Huijie. (2008). Complex network-based time series analysis. Physica A: Statistical Mechanics and its Applications, 387(5), $1381-1386$. 